\title{
Q-methodology and tourism research
}

Dimitrios Stergioua and David Airey

aSchool of Social Sciences, Hellenic Open University, Patras, Greece; bSchool of Management, University of Surrey, Guildford, Surrey GU2 7XH, UK

\begin{abstract}
Tourism research is in the midst of a 'critical turn' away from traditional positivist approaches, towards more reflective and critical paths of inquiry. This paper introduces readers to Q-methodology, a method of research that tourism researchers rarely use and that can provide useful information in critical tourism research concerning the exploration and comparison of subjectivity. The paper presents the fundamentals of the approach and provides examples of its application in tourism and other areas that may directly interest tourism researchers. In so doing, the paper encourages and facilitates the use of Q-methodology amongst tourism researchers interested in enhancing the nature and richness of their methodological alternatives for developing tourism knowledge.
\end{abstract}

Keywords: subjectivity; Q-methodology; Q-sort; tourism research

\section{Introduction}

What Wilson, Harris, and Small (2008, p. 15) describe as a "strait-jacketed fascination with positivistic research," describes tourism research in terms of method. Even though qualitative research approaches initiated much of the seminal work in tourism (Cohen, 1988), even a cursory review of the literature suggests that positivism has been dominating the field. In 1997, for example, Echtner and Jamal asked questions about the evolution of tourism studies and suggested that approaches to tourism research "might be seen to be plagued by the same phobia that dominates all of the social sciences, namely the need to become more "scientific" and the resulting attachment to more traditional positivist methods" (p. 877). Writing in the same year, with particular reference to the quality of tourism research and scholarship, Ryan (1997, p. 3) concluded that tourism researchers are "entrenched in a positivist tradition that was blinding us to developments in the other social sciences". The bias towards positivism was also noted by Riley and Love (2000) and Xiao and Smith (2006). They carried out investigations to identify publication patterns in articles appearing in a selection of tourism journals, regarding the use of qualitative versus quantitative techniques. Covering collectively the content of five journals for the period 1970-2003, they found the dominant paradigm in tourism journals to be positivism.

Change, however, is now underway. In relation to the presence of qualitative studies in tourism research, Dann and Phillips (2001) argue that a recent methodological shift is occurring in the field, towards more qualitative approaches and away from pure quantification. Botterill, Haven and Gale's (2002) analysis of UK dissertations also confirms the increasing influence of qualitative approaches in these studies of tourism. More recently, Tribe $(2005,2007)$ has identified and commented on the emergence of considerably different types of tourism research, 
which offer a counter-balance to positivist approaches. This shift of direction has acquired a number of designations from different researchers. Tribe (2005, p. 5), for instance, calls it "new tourism research", while Ateljevic, Harris, Wilson and Collins, (2005, p. 9) refer to it as the "critical turn" in tourism studies. Whatever the terminology, the present-day initiatives of tourism researchers uniting under this methodological turn are to engage in reflexive, critical and even more subjective forms of inquiry, and search for more in-depth understandings surrounding the tourism phenomenon (e.g., Aitchison, 2001; Botterill, 2003; Pernecky, 2010; Tribe, 2006).

This paper offers a methodological perspective to this literature by detailing an approach to research that endeavours to capture these more qualitative dimensions and provides a useful tool for tourism researchers: namely Q-methodology. Towards this end, the paper provides background on the method and outlines the phases in its application. To ground these phases in examples, the paper draws on previous Q-methodological work in tourism and other areas, such as community development, transport management and environmental issues. The paper draws attention to the synergies between the approach and the current methodological concerns and to the attractions of Q-methodology for tourism researchers currently grappling with this challenge to methodological convention. Use caution in reading this paper; this report suggests rather than exhausts possibilities of Q's contribution to the study of tourism.

\section{Describing Q}

Now almost three quarters of a century old (Stephenson, 1935), Q-methodology can hardly lay claim to the status of a new method for conducting research in the social sciences. As a matter of fact, in 1997 Brown reported that the literature on Q-methodology contained nearly 2500 bibliographic entries, most notably in the fields of communication, political science and philosophy of science, and more recently in the behavioural and health sciences. Today, interest in Stephenson's method continues to rise, with an expanding number of researchers from different intellectual fields adopting $\mathrm{Q}$ in studies of increasing sophistication - e.g., in marketing (Hindman, Mattern, \& Iszler, 2004), public policy (Zografos, 2007), and rural research (Pini, Haslam-McKenzie, \& Previte, 2007). The method's scarce appearance in tourism research is unsurprising as the method has something of "a fugitive status within the larger social scientific community" (McKeown \& Thomas, 1988, p. 11). This may be justifiable by noting that, whereas most social scientists have at least heard of Q-methodology, only a handful have attended seriously to its broader methodological foundations and principles (McKeown \& Thomas, 1988).

Broadly, Q-methodology, which evolves from factor analytic theory, is a means of extracting subjective opinion. Setting statistical procedures aside, however, what Stephenson provides is a means to study the subjectivity involved in any situation. Subjectivity here is not simple partiality. Rather in the lexicon of Q-methodology, subjectivity refers to nothing more than a person's communication of his or her point of view (Goldman, 1999). Q captures subjectivity in operation through a person's self-reference, but this does not render it inaccessible to rigorous examination. Q-methodology operates within the internal frame of reference, not in the sense of a meta-physical subjectivism accessible only to introspection, but in the thoroughly empirical sense of subjective communicability (Stephenson, 1980). In this perspective, Q represents an attempt "to analyse subjectivity, in all its forms, in a structured and interpretable form" (Barry \& Proops, 1999, p. 339).

Due to its involvement with factor analysis, some scholars emphasise the fact that Qmethodology allows a "scientific" study of subjective phenomena (Previte, Pini, \& HaslamMcKenzie, 2007). For example, McKeown and Thomas (1988, p. 12) describe Q-methodology as 
"a method for the scientific study of human subjectivity" and Goldman (1999, p. 589) refers to it as "the science of subjectivity". In this connection, tourism researchers who have embraced reflexive and critical forms of inquiry as a counter-balance to positivist methods may refrain from using Q-methodology due to its quantitative aspects. Nevertheless, even though Q-methodology resembles other quantitative social research methods, in that it requires the application of statistical techniques, it differs from these in ways that have profound implications for its use.

The designation of this method as " $Q$ " intends to differentiate it from " $\mathrm{R}$ " methodology, the statistical methods used for "scientific" research in the social sciences. This difference is illustrated clearly by data collection methods and observation perspectives associated with each of the two approaches (Brown, Durning, \& Selden, 2007). R-methodology emphasises data collection methods whereby respondents are measured for expression of some trait. An external perspective is adopted by placing emphasis on the use of objective and unbiased methods of measurement. The individual's subjective point of view during item response is considered unreliable because each person is thought to possess more or less of the trait or construct under investigation. The power of R-methodology is in abstracting these traits from the individuals who possess them and generalizing the findings to a larger target population (Steelman \& Maguire, 1999).

By contrast, Q-methodology relies on methods of impression (as opposed to objective methods of expression) to discover the subjective meaning or significance items have for respondents. Here, the observation perspective focuses on the internal frame of reference used by each respondent about the relative significance and meaning of individual test stimuli. Q-studies do not yield statistically generalizable results. Instead, the results produce an in-depth portrayal of the patterns of subjective perspectives that prevail in a given situation (Steelman \& Maguire, 1999). It is in this sense that Q-methodology may open up possibilities for contemporary tourism researchers, as it inverts the R-principle of standardised surveys by centering on the subjective experience of the people taking part. As Barker (2008, p. 919) contends, it is this ability to access "significance to me" or individual's subjectivity that mirrors Q's departure from positivist inquiry. The discussion will return to this and other advantages of $\mathrm{Q}$.

\section{Steps in using Q-methodology}

Q-methodology includes five steps. The first step involves identifying a "concourse", which is a technical concept used in Q for a contextual structure of all the possible statements that respondents might make about the subject at hand (Stephenson, 1993). A concourse can take two forms: naturalistic and ready-made (McKeown \& Thomas, 1988). In a naturalistic inquiry, researchers often set up interviews, and statements drawn directly from conversation with the participants are used in the subsequent Q-sort. Ready-made concourses draw upon a range of data sources, such as literature reviews, existing scales or standardized items. In practice, however, researchers can use any number of sources to develop their concourse. Rajé (2007), for example, used research participant statements to obtain a sense of the discourse about travel for different social groups, but turned as well to academic papers, newspaper articles and policy documents as sources of statements. This practice of drawing on a set of interrelated claims from a range of sources, resulted in the development of 180 statements chosen to cover the wide variety of views available on the theme.

In Q-methodology, a concourse is structured in feelings rather than facts; each of these statements expresses feelings and emotions (not necessarily knowledge) driven by immediate experience and lived through personal experience (McKeown, 1990). As Stephenson (1978) 
argues, feelings are subject to fortuitous experiences, in common conversation, singing songs, reading for fun, etc., in countless situations and musings, lived at random. Concourses can include not only verbal statements but might consist of collections of objects, pictures, recordings, and even musical selections. Stephenson himself (1935), for example, conducted early illustrative Q-studies using a set of vases to investigate people's predilection for vases. In the context of tourism research, scholars have employed as "statements" a selection of photographs representing different landscape experiences and visitor activities (e.g., Davis, 2003; Dewar, Li, \& Davis, 2007; Fairweather \& Swaffield, 2001). More commonly, however, Q-methodologists employ sets of statements.

Ideally, the concourse is a statistical population of all possible discourses regarding the studied instance, with a practically infinite number of statements (McKeown, 1990). The universe of statements, therefore, is subject to sampling. Accordingly, the second step of the Q-process is a sampling task where the researcher uses a structure for selection of a Q-sample (or Q-set) from the concourse. As van Exel and de Graaf (2005) suggest, such a structure may be imposed on the concourse, on the basis of some theoretical expectations, or may emerge from further examination of the statements. For example, in a study about service quality in overseas education, the researchers grouped the statements into categories of physical quality, interactive quality and corporative quality (Pereda, Airey, \& Bennett, 2007). In order to arrive at this structure, they reviewed 24 studies related to quality in higher education to establish that these dimensions are well-included in the relevant literature. Alternatively, Yu, Hsu, and Ye (1997) initially categorised statements in their concourse according to their appeal to reason, the senses, social needs, and the ego. They then engaged in an inductive approach in which four appeals of hotel characteristics emerged from these statements: rational appeal, social appeal, ego-enhancing appeal, and sensory appeal.

Eventually the nature of the structure used is of little consequence, provided that the final Q-sample ensures a fair representation of all the major ideas, viewpoints, feelings and opinions that relate to the topic of study (McKeown \& Thomas, 1988). The main concern in a Qmethodological study is not the Q-sample itself (which is, in any event, not considered to impose any meaning a priori), but the overall understanding informing the participants' engagement with the presented items (Stainton Rogers, 1995). In other words, if a Q-set provides a comprehensive list to describe different aspects of the study topic, "the engagement of the participant group with that Q-set will afford a general overview of relevant viewpoints on the subject" (Watts \& Stenner, 2005, p. 76).

Convenience and statistical demands dictate the exact size of the Q-sample (Kerlinger, 1986). Thomson (1981) proposes in small-sample Q-studies that the number of items necessary is a function of the number of individuals taking part in the study, with the number of Q-sample items being at least twice the number of participants. Generally speaking, however, researchers (Stainton Rogers, 1995) consider a Q-sample of 40 to 80 statements as adequate for stable results, without overwhelming participants. To ensure content validity, colleagues or others usually review sample statements in one or more pilot studies (Brown, 2004). Finally, the task of the researcher is to refine statements where necessary, randomly assign them a number for data recoding purposes, and release them for "sorting".

The third step, after the construction of the Q-sample, involves the selection of individuals who will sort the items. These participants are known as the person sample (P-sample). Understanding that Q-methodology, because of its emphasis on individual subjectivity, works well with small numbers of subjects is imperative (Valenta \& Wigger, 1997). For example, in 
their study of the competency of recreation board members, Hurd, Beggs, and Fokken (2009) report using a sample of only eleven. More typically, however, Q-studies work with P sets of 40 to 60 sorters (Stainton Rogers, 1995). Employing a larger sample of participants in a Qmethodological context poses the danger of negating many of the complexities and fine distinctions contained in the data (Watts \& Stenner, 2005). With a smaller number of participants, therefore, "it is more likely that quality and consistency may be maintained" (Rajé, 2007, p. 470).

Because Q-methodology does not seek to make claims to larger representative groups, Qmethodologists do not necessarily depend upon rigorous sampling methods (McKeown \& Thomas, 1988). Most often, the selection of participants is a function of purposive and theoretical sampling (Sexton, Snyder, Wadsworth, Jardine, \& Ernest, 1998). Thus, researchers may select participants who are likely to express distinct and clear perspectives relevant to the problem under consideration and, in this instance, define a factor (Brown, 1980). A study by van Exel, de Graaf, and Rietveld (2004), examining how people approach medium-distance travel decisions, illustrates the process. The researchers purposively solicited car-minded as well as public transport-minded participants for their P set, believing they would have differing viewpoints on the subject. For the purpose of this case, a first wave of respondents was acquired among the authors' circles of family, friends, and acquaintances. Further participants were recruited through snowballing sampling, where existing participants recruited more participants from their circles. This process resulted in 39 people participating in the study. In the end, the point of Qmethodology is to allow individuals to categorize themselves on the basis of the viewpoints they express (Watts \& Stenner, 2005). Its nature is exploratory. In such circumstances, the number of respondents associated with a factor is of less importance than who they are (van Exel \& de Graaf, 2005).

In the fourth step, respondents have to express their views on the topic by placing all statements in a pre-structured Q-sort table (see Figure 1). This is a ranking procedure which Watts and Stenner (2005, p. 77) call "a convenient means of facilitating the (evaluations and) rankings of the participants". In practice, statements are printed on separate cards and respondents rank these according to a condition of instruction. For example, participants may be asked to sort the opinion statements along a simple continuum, with "most agree" on the one end and "most disagree" on the other. No ideal range exists; typical Q-studies, however, employ a range of -5 for items considered "most disagreeable" in the view of the participants, through zero, to +5 for items considered "most agreeable" (van Exel \& de Graaf, 2005).

Figure 1. Example of a Q-sort table.

Most disagree

Most agree

$-5|-4|-3|-2|-1|0| 1|2| 3|4| 5||||||||||||||||||||||||||||||||||||||||||||||||||||||||||||||||||||||||||||||$ |||||||||||||||||||||||| $\mid$

As Figure 1 shows, the Q-table that participants use to sort the statements also dictates the number of items that can be assigned to each ranking position. For this reason it is also known as a "forced Q-sort", because sorters are instructed to conform to a prescribed quasi-normal distribution. Using a forced distribution is optional and it is, in fact, quite possible in Q-studies to allow sorters to distribute the items as they choose among the available response categories (free 
Q-sort). Both Cottle and McKeown (1981) and Brown (1980, 1985) demonstrate that the distribution shape has no major effects on Q-results. Therefore, both the range and the distribution of the Q-sort table are arbitrary and usually depend on the number of statements in the Q-sample (Akhtar-Danesh, Baumann, \& Cordingley, 2009).

The final step of the process is data analysis, which involves the sequential application of three statistical procedures: correlation, factor analysis, and the computation of factor scores (Brown, 2004). Several computer software packages are available to assist with the appropriate analyses. Hence the discussion below provides a very concise overview of what is occurring, rather than a concrete list of instructions. Brown (1980) provides information on the technical and computational aspects of the analysis of Q-sorts.

Typically, Q-analysis begins by computing the correlation matrix of all Q-sorts, which indicates the degree of (dis)agreement in points of view among the participants. Next, this correlation matrix is submitted to factor analysis, with the objective to identify attitudinal groupings, that is, to examine how many basically different Q-sorts are in evidence. In comparison to ordinary factor analysis, Q-factor analysis is an inverse, in that it seeks to cluster respondents rather than variables (Kline, 1994). That is, in Q-mode the factors are clusters of people for a set of variables; people with similar views to the theme of the study who share the same factor.

Whereas persons have associations with clusters in Q-factor analysis, the items comprising the Q-sample have factor scores. For the purpose of this case, factor scores are computed for each of the items in the resulting clusters of respondents, which leads to one representative item configuration per group (ten Klooster, Visser, \& de Jong, 2008). Each factor, therefore, captures a different Q-sort which is shared by the participants loading on this factor (Watts \& Stenner, 2005). At a practical level, this analysis helps Q-researchers to identify those statements that can provide a basis for defining and differentiating factors (Sexton et al., 1998). These statements are used for the interpretation of the composite point of view represented by each factor. Persons with special knowledge or skills in the domain being examined (domain experts) usually carry out this process. As Akhtar-Danesh et al. (2009, p. 768) suggest, "the use of factor analysis in extracting the distinguishing statements and the use of domain experts in interpretation" guide the interpretive process in Q-methodology.

Finally, follow-up interviews with participants after completion of the Q-sort can provide verification of the accuracy of the interpretations (Brown et al., 2007; Vallenta \& Wigger, 1997). In this connection, the interview following the sorting is at least as important as the actual sorting for two reasons (Duenckmann, 2010). First, the Q-sort represents the 'skeleton' of subjectivity, which only becomes interpretable through the comments and reflections of the participants. Second, the interview process allows both the researcher and the test persons to perceive interrelations and inconsistencies in the Q-sorts and to refer to these directly. In this sense, the use of interviews can increase the validity of Q-studies by illuminating the quantitative interpretation of respondents' views through qualitative analysis (Gallagher \& Porock, 2010).

\section{Q-methodology and tourism research}

In 1997, Tribe (1997) argued that the field of tourism studies was narrowly conceived and defined. Subsequent work (Leiper, 2000; Tribe, 2000), brought to light questions of organization, knowledge creation, and power, and provided a significant source of debate, not just about the subject coverage, but also about the conduct of tourism research. The growing engagement with 
critical theory and the developing post-structural literature in the social sciences offered insight to this reflective critique, which signalled a slow retreat from the binds of logical empiricism within which tourism research has been firmly entrenched (Aitchison, 2001). Central to this break from tradition was a challenge to the assumptions of positivism about verifiable facts, objective reality and value neutrality (Tribe, 2001), as well as the introduction of notions such as "power, gender, race, sexuality, embodiment, subjectivity and alternative methodologies" (Wilson, Harris, \& Small, 2008, p. 15).

In tourism studies this critical turn surfaced a little over a decade ago and gained momentum after the turn of the new century, where subsequent developments became evident in the publication of a range of tourism research that embraced more reflexive and critical paths of inquiry (Ateljevic et al., 2005). Select examples of contributions reflecting this new turn include: a personal ethnographic narrative on tourism research epistemologies (Botterill, 2003); a consideration of tourism truths (Tribe, 2006); an exploration of gender perspectives in tourism studies (Aitchison, 2005); a theoretical piece on participation and reflexivity in tourism research (Westwood, Morgan, \& Pritchard, 2006); a study of indigenous engagement in tourism (Nielsen, 2007) and a critical analysis of territories and tribes of tourism studies (Tribe, 2010). At the same time, mainstream academic publishers have produced a number of critical tourism texts dealing with previously underrepresented voices in tourism research (e.g., Ateljevic, Morgan, \& Pritchard, 2007; Phillimore \& Goodson, 2004; Tribe \& Airey, 2007). Three recent Critical Tourism Studies (CTS) conferences took place in Europe (Dubrovnik 2005, Split 2007 and Zadar 2009), with the aim to explore the critical school of thought developing in tourism studies through a focus on issues of embodiment, critical and interpretative modes of tourism inquiry. This work stresses the evidence for change, producing what is now claimed to be the "new tourism research" (Tribe, 2005, p. 5).

While ontological, epistemological and methodological differences may exist, those employing a critical approach generally resist positivist modes of inquiry, embracing paradigms that value diverse, flexible, reflexive and participatory approaches to research (Brookfield, 2005). Critical tourism scholars also hold these ideals in high regard (Wilson et al., 2008). This epistemic orientation is consistent with the methodological initiatives of Q-methodology and this is why many tourism researchers currently coming to grips with the shift to research culture in the field may appreciate the method.

The first attraction of Q-methodology to tourism researchers is its emphasis on the subjective, lived experiences of individuals. As Brown (1996) writes, it is life as lived from the standpoint of the person living it that quantitative procedures typically pass over, and it is subjectivity in this sense that Q-methodology examines. What is of interest to Q-methodology, therefore, is what is meaningful to participants and hence how they make sense and meaning of their realities. This represents a departure from the positivistic idea of definitive truths, which $\mathrm{Q}$ replaces with a fuzzier world of multiple realities. Indeed, Q-methodology, according to Kitzinger (1986, p. 153), rejects the idea of one objective reality and derives new meaning by investigating "numerous truths or multiple versions of reality and then exploring the implications of each". Thus, the increasing number of tourism researchers pursuing accounts from the actors affected by or interested in tourism, rather than simply objectifying their subjects will find Qmethodology interesting. In this connection, Q-methodology emerges as a useful response to the joined calls of Hollinshead (2006) and Westwood et al. (2006) to widen research options and encourage greater participant involvement where the issues facing tourism researchers involve multiple truths. 
A second related factor that may speak to tourism researchers is Q-methodology's capacity to circumvent the usual control of the researcher on imposing meaning and structure. Within the context of Q-methodology, researchers gain insight into the investigated topics by reference to the participants in the study. They provide the starting point. This is in contrast to positivist tourism research, where the researcher has often constructed meaning a priori (Selby, 2004). As Tribe (2001) explains, methods embedding such meaning appear to be value-free, clouding the possibility that differences of values, meaning or interpretation may have informed responses to the whole exercise. In fact, the writings of a number of tourism researchers challenge these methods for this lack of consideration (e.g., Echtner \& Jamal, 1997; Rojek \& Urry, 1997). Qmethodology, on the other hand, does not impose meanings a priori. Instead, it asks the participants to decide what has value and significance from their perspective. The emphasis is on the meanings that the Q-sorters impose a posteriori (Brown, 1980). This basis of Q-methodology fits comfortably with much contemporary tourism research. For example, both Noy (2004) and Uriely (2005) affirm that tourism studies often disregard details of the lived experience of the researched. They implore tourism researchers to offer a voice to the researched and, therefore, attempt to reduce the power of the researcher.

Its capacity to democratize the research process is a final reason for using Q-methodology. A significant part of the critical turn in tourism studies is promoting research approaches that value the participation of people themselves in key deliberations and decisions that affect their lives (Sheena, 2007); this is a democratic vision. Following the preceding discussion, Q is already being quite democratic in how the method allows participants to speak for themselves. However, the potential in $\mathrm{Q}$ for democratizing research goes beyond this view. A study of contested environmental discourses by Barry and Proops (1999) illustrates the point. They highlight the importance of these discourses in constructing socially acceptable and effective environmental policies:

If [Q] allows respondents who ultimately have to live with the consequences of environmental policy to be included in determining or identifying a problem, it is more likely that the policy will be acceptable and thus more likely to be effective. (Barry \& Proops, 1999, pp. 344-345)

In this instance, Q may have a role to play in the development of more democratic forms of policy formulation, in that it allows those who have to live with policies some part in determining them. By identifying alternative social interests and the knowledge that might best serve them, Q also appears to embrace the idea of the search for the "good life for tourism" - a better production and consumption of tourism - that is central in critical tourism research (Tribe, 2007, p. 30).

Q-methodology has a number of other merits just as a range of shortcomings exist. Rather than providing an exhaustive review of these, this paper draws attention to the epistemic affinities between the method and the methodological turn in tourism research. This is an orientation that began to emerge in tourism studies in the late 1990s, and has been gaining wide acceptance among contemporary tourism scholars. Those researchers favoring positivist traditions would necessarily present different views of the method. After all, one's own ontological and epistemological stance largely dictates views about the praises and criticisms of any method.

Having said this, however, it is important to highlight one final characteristic of Qmethodology, which will interest this latter group of tourism researchers. This is that Qmethodology does not necessarily supplant more traditional objective research approaches. As Brown puts it (1986, p. 67), "in sum, surveys and polls [R method] reveal bulges of proportions that exist in the aggregate, and Q can supplement this effort by showing, however tentatively, how these bulges can be understood and the nature of the intellectual reasoning that is producing them" 
Stergiou and colleagues (2008) offer an example; they studied the main factors associated with good performance by teachers in tourism higher education. Their study includes four interrelated segments. In the first segment, the work draws on literature from the field of education more generally to arrive at a set of dimensions of teaching evaluation. During the second segment, the researchers undertook a literature search and review to identify 140 statements expressing these dimensions. The third segment involved asking two small samples of tourism teachers and students to Q-sort the statements. In the fourth segment, the results from the two Q-samples were compared, and 60 statements were selected for use in a questionnaire survey with a large, purposive sample of tourism students using $\mathrm{R}$ methodology. In this sense, researchers can use Q-methodology to tease out perspectives that are participant-defined and very detailed. Then they can match survey respondents to these perspectives, providing indications of their prevalence among the population and of their associations with other variables (Danielson, 2009). Such a combination of $Q$ and $R$ is "legitimate and intriguing, though rare" (van Exel et al., 2004, p. 207).

\section{Conclusions}

Admittedly, the scenario above is different to usual applications of Q-methodology as they appear in the literature. Nevertheless, the scenario serves to underscore an important aspect of Qmethodology. Specifying clearly and unambiguously rules for deciding just what research issues Q-methodology can and should tackle is impossible (Kerlinger, 1972). Indeed, as the bibliography to this paper suggests, researchers use Q-methodology in a variety of settings, over an equally wide variety of topics. Rather than list a range of possible topics to research with Q, therefore, this paper focuses on presenting a view of the approach that is consistent with changes in methodological and epistemological thinking. Indeed, as a framework for the study of subjectivity as both process and context, $\mathrm{Q}$ sets out a project that offers an alternative to existing methodological perspectives. Q-method may open up possibilities for contemporary tourism researchers, to enhance the nature and richness of the methodological alternatives for developing tourism knowledge. 
References

Aitchison, C. (2001). Theorizing other discourses of tourism, gender and culture: Can the subaltern speak (in tourism)? Tourist Studies, 1, 133-147. doi: 10.1177/146879760100100202

Aitchison, C. (2005). Feminist and gender perspectives in tourism studies: The social-cultural nexus of critical and cultural theories. Tourist Studies, 5, 207-224. doi:

$10.1177 / 1468797605070330$

Akhtar-Danesh, N., Baumann, A., \& Cordingley, L. (2009). Q-methodology in nursing research: A promising method for the study of subjectivity. Western Journal of Nursing Research, 30, 759-773. doi: 10.1177/0193945907312979

Ateljevic, I., Harris, C., Wilson, E., \& Collins, F.L. (2005). Getting entangled: reflexivity and the critical turn in tourism studies. Tourism Recreation Research, 30, 9-21.

Ateljevic, I., Morgan, N., \& Pritchard, A. (Eds.). (2007). The critical turn in tourism studies: Innovative research methodologies. Oxford \& Amsterdam: Elsevier.

Barker, J. (2008). Q-methodology: An alternative approach to research in nurse education. Nurse Education Today, 28, 917-925. doi: 10.1016/j.nedt.2008.05.010

Barry, J., \& Proops, J. (1999). Seeking sustainability discourses with Q methodology. Ecological Economics, 28, 337-345. doi: 10.1016/S0921-8009(98)00053-6

Botterill, D. (2003). An autoethnographic narrative on tourism research epistemologies. Loisir et Société, 26, 97-110.

Botterill, D., Haven, C., \& Gale, T. (2002). A survey of doctoral theses accepted by universities in the UK and Ireland for studies related to tourism, 1990-1999. Tourist Studies, 2, 283-311. doi: $10.1177 / 14687976020023004$

Brookfield, S. (2005). The power of critical theory for adult learning and teaching. Berkshire: Open University Press.

Brown, S. R. (1980). Political subjectivity: Applications of $Q$ methodology in political science. New Haven, CT: Yale University Press.

Brown, S.R. (1985). Comments on the search for structure. Political Methodology, 11, 109-117.

Brown, S.R. (1986). Q technique and method: Principles and procedures. In W.D. Berry \& M.S. Lewis-Beck (Eds.), New tools for social scientists: Advances and applications in research methods (pp. 57-76). Beverly Hills, CA: Sage.

Brown, S.R. (1996). Q methodology and qualitative research. Qualitative Health Research, 6, 
Brown, S.R. (1997). The history and principles of $Q$ methodology in psychology and the social sciences. Kent, $\mathrm{OH}$ : Department of Political Science, Kent State University. Retrieved from: http://facstaff.uww.edu

Brown, S.R. (2004). Q methodology. In M.S. Lewis-Beck, A. Bryman, \& T.F. Liao (Eds.), The SAGE encyclopedia of social science research methods (Vol. 3, pp. 887-888). Thousand Oaks, CA: Sage.

Brown, S.R., Durning, D.W., \& Selden, S.C. (2007). Q-methodology. In K. Yang \& G.J. Miller (Eds.), Handbook of research methods in public administration (2 ${ }^{\text {nd }}$ ed., pp. 721-764). Boca Raton, FL: CRC Press.

Cohen, E. (1988). Traditions in the qualitative sociology of tourism. Annals of Tourism Research, 15, 29-46. doi: 10.1016/0160-7383(88)90069-2

Cottle, C.E., \& McKeown, B.F. (1981). The forced-free distinction in Q technique: A note on unused categories in the Q sort continuum. Operant Subjectivity, 3, 58-63.

Danielson, S. (2009). Q method and surveys: Three ways to combine Q and R, Field Methods, 21, 219-237. doi: 10.1177/1525822X09332082

Dann, G.M.S., \& Phillips, J. (2001). Qualitative tourism research in the late twentieth century and beyond. In B. Faulkner, G. Moscardo \& E. Laws (Eds.), Tourism in the twenty-first century (pp. 247-265). London: Continuum.

Davis, C.H. (2003, October). Traveler perceptions of a destination as a source of new product concepts: $Q$-method study of summer visitors to the Bay of Fundy. Paper presented at the Tourism and Travel Research Association (TTRA) Canada Annual Conference, Saint John, New Brunswick.

Dewar, K., Li, W.M., \& Davis, C.H. (2007). Photographic images, culture, and perception in tourism advertising: A Q methodology study of Canadian and Chinese students. Journal of Travel and Tourism Marketing, 22, 35-44. doi: 10.1300/J073v22n02_03

Duenckmann, F. (2010). The village in the mind: Applying Q-methodology to reconstructing constructions of rurality. Journal of Rural Studies, 26, 284-295. doi:10.1016/j.jrurstud.2010.01.003

Echtner, C.M., \& Jamal, T.B. (1997). The disciplinary dilemma of tourism studies. Annals of Tourism Research, 24, 868-883. doi: 10.1016/S0160-383(97)00060-1

Fairweather, J.R., \& Swaffield, S.R. (2001). Visitor experiences of Kaikoura, New Zealand: An interpretive study using photographs of landscapes and Q method. Tourism Management, 22, 
Gallagher, K., \& Porock, D. (2010). The use of interviews in Q-methodology: Card content analysis. Nursing Research, 59, 295-300. doi: 10.1097/NNR.0b013e3181e4ffff

Goldman, I. (1999). Q-methodology as process and context in interpretivism, communication, and psychoanalytic psychotherapy research. The Psychological Record, 49, 589-604.

Hindman, D.B., Mattern, J., \& Iszler, J. (2004). Applications of Q methodology to in class advertising research projects. Journal of Advertising Education, 8, 17-28.

Hollinshead, K. (2006). The shift to constructivism in social inquiry: Some pointers for tourism studies. Tourism Recreation Research, 31, pp. 43-58. Retrieved from http://www.trrworld.org

Hurd, A.R., Beggs, B.A., \& Fokken, P. (2009). Board member competency: A Q methodology approach. Journal of Unconventional Parks, Tourism \& Recreation Research, 2, 35-42. Retrieved from http://juptrr.asp.radford.edu/

Kerlinger, F.N. (1972). Q methodology in behavior research. In S.R. Brown \& D.J. Brenner (Eds.), Science, psychology, and communication (pp. 3-38). New York, ??: Teachers College Press.

Kerlinger, F.N. (1986). Foundations of behavioral research. New York, NY: Holt, Rhinehart and Winston.

Kitzinger, C. (1986). Introducing and developing Q as a feminist methodology: A study of accounts of lesbianism. In S. Wilkinson (Ed.), Feminist social psychology: Developing theory and practice (pp. 151-172). Philadelphia, PA: Open University Press.

Kline, P. (1994). An easy guide to factor analysis. New York, NY: Routledge.

Leiper, N. (2000). An emerging discipline. Annals of Tourism Research, 27, 805-809. doi: 10.1016/S0160-7383(99)00118-8

McKeown, B.F. (1990). Q methodology, communication, and the behavioral text. Electronic Journal of Communication/La Revue Electronique de Communication, 1. Retrieved from: http://www.cios.org/www/ejcmain.htm

McKeown, B.F., \& Thomas, D.B. (1988). Q Methodology. Newbury Park, CA: Sage.

Nielsen, N. (2007). The Bhiamie Dreaming Cooperative: Regional self-determination in Aboriginal tourism planning in north-west New South Wales. In J. Buultjens \& D. Fuller (Eds.), Striving for sustainability: Case studies in indigenous tourism (pp. 211-246). Lismore: Southern Cross University. 
Noy, C. (2004). This trip really changed me: Backpackers' narratives of self-change. Annals of Tourism Research, 31, 78-102. doi: 10.1016/j.annals.2003.08.004

Pereda, M., Airey, D., \& Bennett, M. (2007). Service quality in higher education: The experience of overseas students. Journal of Hospitality, Leisure, Sport \& Tourism Education, 6, 55-67. doi: 10.3794/johlste.62.160

Pernecky, T. (2010). The being of tourism. The Journal of Tourism and Peace Research, 1, 1-15.

Phillimore, J., \& Goodson, L. (Eds.). (2004). Qualitative research in tourism. London: Routledge.

Previte, J., Pini, B., \& Haslam-McKenzie, F. (2007). Q methodology and rural research.

Sociologia Ruralis, 47, 135-147. doi:

10.1111/j.1467-9523.2007.00433.x

Rajé, F. (2007). Using Q methodology to develop more perceptive insights on transport and social inclusion. Transport Policy, 14, 467-477. doi: 10.1016/j.tranpol.2007.04.006

Riley, R.W., \& Love, L.L. (2000). The state of qualitative tourism research. Annals of Tourism Research, 27, 164-187. doi: 10.1016/S0160-7383(99)00068-7

Rojek, C., \& Urry, J. (1997). Transformations of travel and theory. In C. Rojek \& J. Urry (Eds.), Touring cultures: Transformations of travel and theory (pp. 1-19). London: Routledge.

Ryan, C. (1997). Tourism: A mature subject discipline? Pacific Tourism Review, 1, 3-5.

Selby, M. (2004). Understanding urban tourism: Image, culture and experience. New York: I.B. Tauris.

Sexton, D., Snyder, P., Wadsworth, D., Jardine, A., \& Ernest, J. (1998). Applying Q methodology to investigation of subjective judgments of early intervention effectiveness. Topics in Early Childhood Special Education, 18, 95-107. doi: 10.1177/027112149801800205

Stainton Rogers, R. (1995). Q methodology. In J.A. Smith, R. Harre, \& L. Van Langenhove (Eds.), Rethinking methods in psychology (pp. 178-192). London: Sage.

Steelman, T.A., \& Maguire, L.A. (1999). Understanding participant perspectives: Q-methodology in national forest management. Journal of Policy Analysis and Management, 18, 361-388. doi: 10.1002/(SICI)1520-6688(199922)18:3<361::AID-PAM3>3.0.CO;2-K

Stephenson, W. (1935). Correlating persons instead of tests. Character and Personality, 4, 17-24. doi: 10.1111/j.1467-6494.1935.tb02022.x

Stephenson, W. (1978). Concourse theory of communication. Communication, 3, 21-40.

Stephenson, W. (1980). Consciring: A general theory for subjective communicability. In D. 
Nimmo (Ed.), Communication yearbook 4 (pp. 7-36). New Brunswick, NJ: Transaction.

Stephenson, W. (1993). Introduction to Q-methodology. Operant Subjectivity, 17, 1-13.

Stergiou, D., Airey, D., \& Riley, M. (2008). Making sense of tourism teaching. Annals of Tourism Research, 35, 631-649. doi: 10.1016/j.annals.2008.03.001

ten Klooster, P.M., Visser, M., \& de Jong, M.D.T. (2008). Comparing two image research instruments: The Q-sort method versus the Likert attitude questionnaire. Food Quality and Preference, 19, 511-518. doi: 10.1016/j.foodqual.2008.02.007

Thompson, B. (1981, January). Factor stability as a function of item variance. Paper presented at the annual meeting of the Southwest Educational Research Association, Dallas, TX.

Tribe, J. (1997). The indiscipline of tourism. Annals of Tourism Research, 24, 638-657. doi: 10.1016/S0160-7383(97)00020-0

Tribe, J. (2000). Indisciplined and unsubstantiated. Annals of Tourism Research, 27, 809-813. doi: 10.1016/S0160-7383(99)00122-X

Tribe, J. (2001). Research paradigms and the tourism curriculum. Journal of Travel Research, 39, 442-448. doi: 10.1177/004728750103900411

Tribe, J. (2005). New tourism research. Tourism Recreation Research, 30(2), 5-8.

Tribe, J. (2006). The truth about tourism. Annals of Tourism Research, 33, 360-381. doi: 10.1016/j.annals.2005.11.001

Tribe, J. (2007). Critical tourism: Rules and resistance. In I. Ateljevic, N. Morgan, \& A. Pritchard (Eds.). The critical turn in tourism studies: Innovative research methodologies (pp. 29-40). Oxford: Elsevier.

Tribe, J. (2010). Tribes, territories and networks in the tourism academy, Annals of Tourism Research, 37, 7-33. doi: 10.1016/j.annals.2009.05.001

Tribe, J., \& Airey, D. (Eds.). (2007). Developments in tourism research. Oxford, Elsevier.

Uriely, N. (2005). The tourist experience: Conceptual developments. Annals of Tourism Research, 32, 199-216. doi: 10.1016/j.annals.2004.07.008

Valenta, A.L., \& Wigger, U. (1997). Q-methodology: Definition and application in health care informatics. Journal of the American Medical Informatics Association, 4, 501-510. doi: 10.1136/jamia.1997.0040501

van Exel, J., \& de Graaf, G. (2005). Q-methodology: A sneak preview. Retrieved from http://www.qmethodology.net/PDF/Q-methodology\%20-\%20A\%20sneak\%20preview.pdf 
van Exel, J., de Graaf, G., \& Rietveld, P. (2004). Getting from A to B: Operant approaches to travel decision making. Operant Subjectivity, 27, 194-216.

Watts, S., \& Stenner, P. (2005). Doing Q methodology: Theory, method and interpretation. Qualitative Research in Psychology, 2, 67-91. doi: 10.1191/1478088705qp022oa

Westwood, S. (2007). What lies beneath? Using creative, projective and participatory techniques in qualitative tourism inquiry. In I. Ateljevic, N. Morgan, \& A. Pritchard (Eds.). The critical turn in tourism studies: Innovative research methodologies (pp. 293-316). Oxford: Elsevier.

Westwood, S., Morgan, N., \& Pritchard, A. (2006). Situation, participation and reflexivity in tourism research: Furthering interpretive approaches to tourism enquiry. Tourism Recreation Research, 31(2), 33-41.

Wilson, E., Harris, C., \& Small, J. (2008). Furthering critical approaches in tourism and hospitality studies: Perspectives from Australia and New Zealand. Journal of Hospitality and Tourism Management, 15, 15-18.

Xiao, H., \& Smith, S.L.J. (2006). The making of tourism research: Insights from a social sciences journal. Annals of Tourism Research, 33, 490-507. doi: 10.1016/j.annals.2006.01.004

Yu, L., Hsu, M.L., \& Ye, K.D. (1997). A study of the ideal types of five star hotels in Taiwan. Proceedings of the National Science Council, Republic of China, Part C: Humanities and Social Sciences, 8, 58-67.

Zografos, C. (2007). Rurality discourses and the role of the social enterprise in regenerating rural Scotland. Journal of Rural Studies, 23, 38-51. doi: 10.1016/j.jrurstud.2006.04.002 